Int.J. Hum. Soc. Dev. Res.

ISSN (P):2521-1439; ISSN (E):2523-4331

Volume 3, № 1, 2019. 24-31

DOI: $10.30546 / 2523-4331.2019 .3 .1 .24$

\title{
A NEW APPROACH IN ADDICTION TREATMENT
}

\author{
Aslı YAYAK \\ Bursa Technical University, Turkey
}

\section{(C) The Author(s) 2019}

\section{ABSTRACT}

Drug addiction in DSM-V in the diagnostic and statistical manual of psychological disorders; It is defined as the fact that people continue to use the drug even though they have a negative condition due to the use of a drug. Behind people's addictive drug using, there are many reasons for use from pleasure to use to escape from stress and anxiety. As opposed to that to become an addict is fast and easy, to get rid of them is hard and it requires an intense and strict treatment process. There are various treatment methods for drug addiction. Biological therapy, psychosocial treatment and behavioral approach therapy are the most preferred and functional methods in current use. In this study, literature related to virtual reality applications in drug addiction treatment which is a part of behavioral approach therapy, has been reviewed and information on the subject has been compiled. Virtual reality refers to computer-generated simulations or environments that people experience with technological applications. The aim of virtual reality is to simulate sensory information such as sound, tactile and visual inputs from the real world through artificial means. In recent years, virtual reality technology has become quite popular due to the increasing number of head-mounted displays (HMD). These virtual reality helmets are often devices that look like visors or helmets. This device abstracts the person from the visual stimuli of the real world while simultaneously immersing the person to the virtual world. The must-have feature of virtual reality studies is that the perception of "existence" of participants in the virtual reality spatially and the feeling of being immersed in that virtual world. While the training for physicians and surgeons was used as a experimental simulation tool, it provided an interactive reality for psychological change. For example, in the treatment of phobias, individuals have been adapted with systematic virtual reality exposure therapies by presenting virtual worlds associated with their phobias.

(C)2019.All rights reserved

\section{ARTICLE HISTORY}

Received: 09/01/2019

Accepted: 29/03/2019

Published online: 01/04/2019

\section{KEYWORDS}

Virtual reality application, drug addiction, behavioral approach therapy, computer-generated simulations.

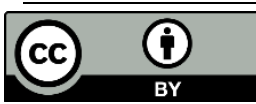

www.ijhsdr.com 


\section{Introduction}

The Green Crescent, which has been involved in the fight against smoking, drugs, alcohol addiction and harmful habits, has been working to preserve the health of the population and especially the young population, defines the physiology, social life and psychology of individuals as an important disease that negatively affects them. Addiction is a condition in which a person continues to have the habit of using this drug although he / she have significant problems in his / her life due to using of a certain drug. There are more than one types of addiction. The Green Crescent has listed the various types of addiction as follows: Tobacco and Cigarette Addiction, Alcohol Addiction, Drug Abuse, Technology Addiction and Gambling Addiction. In this research, we will discuss the application of virtual reality which will be used in many parts of the world in drug addiction and its treatment.

Drug addiction in DSM-5 (APA, 2013) in the diagnostic and statistical manual of psychological disorders; It is defined as the fact that people continue to use the drug even though they have a negative condition due to the use of a drug. DSM-5 contains 11 different criteria for drug addiction diagnosis. These criteria include work and health problems arising from drug use, continuous use of drugs despite negative social consequences, development of withdrawal symptoms and tolerance. To get a diagnosis of drug addiction, it's needed to be sure that the individual shows reaction to two or more of these criteria. (Nolen-Hoeksema, 2014; American Psychiatric Association, 2013).

Behind people's addictive drug using, there are many reasons for use from pleasure to use to escape from stress and anxiety. For example, drug abuse of film stars and successful athletes may be a role model for society and especially for adolescents. Ease of procuring the illegal and addictive drugs, the desire to try something new and peer pressure are the other reasons that affect drug use. Studies in the literature have shown that genetic predisposition plays a role in drug addiction as well. As opposed to that to become an addict is fast and easy, to get rid of them is hard and it requires an intense and strict treatment process (Feldman, 2011).

There are various treatment methods for drug abuse. Biological therapy is one of them. By this type of medication, drug addictions of individuals are reduced and their stable conditions are maintained. While some addicts can resist withdrawal symptoms with the contribution of spiritual support from their environment; others need medical treatment. The other method of treatment is; psychosocial treatment. This type of treatment has proven successful in the treatment of drug addiction and includes many cognitive and behavioral techniques. These techniques are combined in five objectives. The first one is that individuals are motivated to quit the drug they are addicted. 
The second is to teach people ways to cope with stress and negative feelings. The third is to change the reinforcements that lead to drug use in the individual's life. The fourth, increasing the emotional support that people get from their families and their environment, and the fifth is the support of the combination of medical treatment and psychotherapy (Nolen-Hoeksema, 2014). The major therapy method used in the treatment of drug addiction psychotherapy is Behavioral Approach therapy.

In the basis of the Behavioral Approach, the purpose of the therapy is to reinforce the desired behavior and to eliminate the unwanted behavior by punishment. The basic assumption of this approach is that both normal and abnormal behaviors are realized by learning. Abnormally behaving people are either people who have not learned how to cope with the problems they face in their daily life, or some reinforcements play a role in the continuity of these abnormal behaviors. In order to change the abnormal behavior, this approach states that people should interchange their behaviors and skills with new behaviors and forget their incompatible behaviors. Behavioral approach does not need to examine the past experiences and moods of individuals. Rather than seeing abnormal behavior as an underlying symptom of the problem, it sees abnormal behavior as the problem itself, and this behavior should be changed. The aim of this therapy is to ensure that people live more productively by changing their incompatible behaviors (Feldman, 2011).

The history of behavioral therapy is based on the work of Ivan Pavlov. By examining the digestive system of dogs, Ivan Pavlov observed that when the meal was given, the saliva-excreting dogs excrete saliva into another stimulus to which they were repeatedly exposed at the time of the meal, and thus discovered the classical condition during their studies. Based on the findings of Pavlov, the therapists, who united under the roof of behaviorism approach, based all behaviors on the basis of conditioning. In other words, behavioral therapists argued that all behaviors were acquired by learning (Feldman, 2011). Techniques used in behavioral approach therapy are mostly based on classical conditioning. One of these therapy techniques is "aversive conditioning". Aversive conditioning is a type of therapy in which the frequency of this behavior is aimed to be reduced by associating the unwanted behavior with an unwanted, unpleasant stimulus. For example, the therapist may associate alcohol with a drug that causes intense nausea and vomiting for aversive conditioning. After pairing the couple several times, the person will associate the alcohol with vomiting and it will be less attractive to drink alcohol. Although aversive therapy is quite good in the treatment of drug addiction such as alcoholism and in the treatment of some sexual disorders, its long-term effectiveness is a matter of debate. There are also significant ethical concerns about aversive therapy, which can be used only in extreme cases, such as in the treatment of electric shock, where there is a danger of self-harm. Obviously, aversive therapy is an important technique for eliminating mismatched behaviors and reactions 
for a certain period of time; it is a break that provides the opportunity to encourage more adaptable behaviors of individuals (Feldman, 2011).

Another treatment of classical conditioning is systematic desensitization. In systematic desensitization, the subject is gradually exposed to anxiety producing stimuli and this process is matched with relief, so that the anxiety response is quenched. With systematic desensitization, psychological problems that cause anxiety can be solved. Primarily, the behaviourist therapist trains individuals with relaxation techniques and teaches them how to feel good by relaxing their bodies. Then, a list of sequential hierarchies is created according to the severity of the situations related to anxiety. After the techniques of relaxation are being learned and hierarchy is created, the patient learns to relate two types of reaction. Therefore, the therapist asks the patient to take a comfortable state of mind, and then tells the patient to imagine that he is experiencing the first step in the created hierarchy. The therapist proceeds to the next step as long as the steps of the hierarchy are comfortable. Thus, the last step is reached and it's asked the patient to imagine the situation in which the patient is experiencing anxiety. At this stage of imagination, the therapy meets the objective by the reactions of the patient which are calm and far from anxiety (Feldman, 2011).

Although systematic desensitization is a proven practice, it has been replaced by exposure therapy which is a simpler form of therapy. Exposure is a behavioral treatment that is used for anxiety that people face with their fears suddenly or gradually. Unlike systematic depersonalization, relaxation training is not provided. Exposure provides an extinction of anxiety and avoidance of anxiety, and has proven to be a successful technique in studies. In most cases, therapists prefer to expose the subject gradually to the situations in which the individuals are scared or they avoid. For example, firstly some dog videos may be made a patient who is afraid of dogs. Gradually the exposure approaches the real life and a dog is left in the room where he/she is and finally the patient is struck off the level which he/she is able to touch the dog and feed him (Feldman, 2011). In the recent years, exposure technique, which is one of the techniques of behavioral therapy used in the treatment of drug addiction, has been applied with the help of virtual reality application. In this application, cue-reactivity is used so that the addicted individuals can learn to resist the drugs they are addicted to and reminder clues to use those substances. Cue-reactivity is a frequently used topic in drug abuse studies. Drug addicts are vulnerable to drug use when they encounter a stimulus associated with the drug used. These individuals develop a conditioned response to the previously associated stimulus with the drug used. These reactions lead to a resumption and continuation of drug use (Carter and Tiffany, 1999). In one study, Bordnick (2009) et al. examined 20 untreated cannabis users in terms of subjective desire level and attention to the clues that reminds of the use of cannabis by involving them in the virtual reality environment and in a neutral virtual reality environment in which there are some clues reminding the use of cannabis. During the study, participants were exposed to 4 
different virtual reality environments equipped with auditory, visual, sensory and vibration stimuli. In one of these virtual realities, there is a party environment in which there are people full of using cannabis, and in the other one there is a room filled with hemp materials where there are no people. The other two neutral virtual reality rooms include digital art gallery and nature videos; there is nothing about cannabis in these rooms. The subjective desire of use and attention to the clues were significantly higher in the virtual reality rooms having hemp than in the neutral virtual reality rooms. These findings have shown that the cue-reactivity can be performed with the help of virtual reality for research and treatment of cannabis addiction.

Virtual reality refers to computer-generated simulations or environments that people experience with technological applications. The aim of virtual reality is to simulate sensory information such as sound, tactile and visual inputs from the real world through artificial means. In recent years, virtual reality technology has become quite popular due to the increasing number of head-mounted displays (HMD). These virtual reality helmets are often devices that look like visors or helmets. This device abstracts the person from the visual stimuli of the real world while simultaneously immersing the person to the virtual world (Durl, Dietrich, Pang, Potter and Carter, 2018; Bordnick, Carter and Traylor, 2011).

Virtual reality technology is very new, emerged in the late 1980s, but after since it was founded expensive, mostly it was omitted. In recent years, with the rapid development of technology, virtual reality has started to attract attention again and this development has been most exciting for researchers and health education. With virtual reality technology, researches on alcohol addiction has accelerated and continues at full speed (Durl, Dietrich, Pang, Potter, and Carter, 2018).

Health sciences and virtual reality technology were first introduced in 1990 . The must-have feature of virtual reality studies is that the perception of "existence" of participants in the virtual reality spatially and the feeling of being immersed in that virtual world (Durl, Dietrich, Pang, Potter and Carter, 2018). While the training for physicians and surgeons was used as a experimental simulation tool, it provided an interactive reality for psychological change. For example, in the treatment of phobias, individuals have been adapted with systematic virtual reality exposure therapies by presenting virtual worlds associated with their phobias (Jerdan, Grindle, Van Woerden and Boulos, 2018).

In the treatment of many psychological disorders, especially in anxiety disorders requiring Cognitive-Behavioral therapy, patients are often confronted and exposed to situations in which they fear. In this way, patients become accustomed to situations related to anxiety over time and change their beliefs about the probability or catastrophic nature of their feared results, i.e. cognitive reassessment occurs. In real life, 
exposure is highly effective, but the processes of finding and resolving real-life exposure conditions in such situations as trauma-related scenes, thunder, height, injury, addiction, and phobia may be time-consuming, impractical, and sometimes even impossible. Exposure through virtual reality is an extension of the traditional exposure method and is used in several treatments of psychological disorders that cause many anxiety and fear symptoms. In order to cope with these limitations of real-life exposure,

virtual reality can be effectively used in stimulating feared situations and thereby treating psychological disorders (Gega, 2017; Motraghi, Seim, Meyer and Morissete, 2014). Also in real life in exposure therapy, being exposure of some addictive individuals to the environments they're addicted to is difficult for them when it's traumatic as well. For this reason in some studies, the rate of quitting and not responding can reach up to $50 \%$. Exposure method can be applied more easily by using technology in such patients. In this sense, virtual reality has been used as a tool for exposure and has achieved positive results in the treatment of various anxiety disorders including specific phobias, social phobia, panic disorder and PTSD (Gonçalves, Pedrozo, Coutinho, Figueira and Ventura, 2012).

The interest in the virtual reality method is increasing in the field of clinical psychology, especially in the treatment of psychological disorders that cause anxiety. It is also an objective tool for monitoring physiological responses in the evaluation of emotional situation (Jang, Kim, Wiederhold, Wiederhold and Kim, 2002).

In the literature, studies that measure virtual reality applications in drug addiction are quite lacking. Current studies mostly examined alcohol addiction. Previous studies have shown that studies carried out with reminder expulsion therapy are effective in developing resistance against drug in different risk groups. The studies have been tried to find out how to increase the ability of being resistant to alcohol use by virtual reality application and exposing reminder method. In the studies of exposure to the reminders, the desire to drink alcohol was revealed through virtual reality, and it was aimed to educate individuals who are prone to risk taking behavior on both virtualization and resistance by virtual reality (Durl, Dietrich, Pang, Potter and Carter, 2018).

Durl, Dietrich, Pang, Potter, and Carter (2018) conducted 8 studies examining the role of the virtual reality method in alcohol addiction studies to until today by making a literature review to explain the prevalence and effectiveness of use of virtual reality in alcohol use research. Six of the studies were conducted in America, one in Canada and one in South Korea. The virtual reality helmet was used in three studies and the other five studies were conducted with interactive computer programs. Five studies, two studies and one study are respectively implemented with cross-sectional, pretestposttest and longitudinal study design. Virtual reality studies in alcohol addiction were 
applied in 3 different areas. The first one is the cue-exposure therapy, in which the reactions of yearning for substances are formed in participants. In the second field, driving simulation was used. The relationship between alcohol and neural activity was investigated by this method. The third area focuses on the education of health professionals. Only one was used to help the treatment of alcohol-related problems of health professionals. All three studies wanted to see the effect of reminders on the desire and urge to drink. Reaction to a reminder is a response that can be observed when individuals encounter alcohol or other drugs to which they are addicted, and it represents repetitive behaviors. Although these studies differ specifically in their interest, they all wondered the effect of virtual reality on alcohol. Studies have shown that virtual reality method can be simulated to the real world and participants can perceive the virtual objects in the environment as real. The results in educational use have improved the learning process of students through the virtual nature and the convincing nature of virtual reality and encouraged students to enhance their level of knowledge.

Most alcohol and virtual reality studies focus on treatment rather than focusing on preventing alcohol use problems or reducing alcohol use. Hadley et al. (2014) examined the peer pressure factor with virtual peers in alcohol and drug use. Peer pressure played an important role in alcohol and drug use for the first time.

The virtual reality therapy is applied in many countries aimed at combating addiction to the new application will be implemented newly in Turkey. Assoc. Dr. Alptekin Çetin, who has began studies at NPIstanbul Hospital of Üsküdar University, says that thanks to this application, addicted individuals can develop their ability to say "no" to the drug that they have developed addictions ("Virtual Reality" treatment in Addiction, 2018).

\section{Disclosure statement}

No potential conflict of interest was reported by the author.

\section{Contact Information}

E-mail: ayayak@gmail.com 


\section{References and notes:}

American Psychiatric Association. (2013). Diagnostic and Statistical Manual of Mental Disorders (5. Edition). Washington, DC: Author.

What is Addiction?. Yeşilay. https://www.yesilay.org.tr/tr/bagimlilik/bagimlilik-nedir

Virtual Reality Applications in Drug Addiction Treatment. (2018). NP İstanbul Beyin Hastanesi, https://npistanbul.com/bagimlilikta-sanal-gerceklik-tedavisi.

Bordnick, P. S., Carter, B. L. \& Traylor A. C. (2011). What virtual reality research in addictions can tell us about the future of obesity assessment and treatment. Journal of Diabetes Science and Technology, 5(2),pp.265-71. doi: [10.1177/193229681100500210]

Bordnick, P. S., Copp, H. L., Traylor, A., Graap, K. M., Carter, B. L., Walton, A. \& Ferrer, M. (2009). Reactivity to cannabis cues in virtual reality environments. Journal of psychoactive drugs, 41(2), pp.105-12. doi: [10.1080/02791072.2009.10399903]

Carter, B. L. \& Tiffany, S. T. (1999). Meta-analysis of cue-reactivity in addiction research. Addiction, 94(3), 327-40. doi: 10.1046/j.1360-0443.1999.9433273.x

Durl, J., Dietrich, T., Pang, B., Potter, L. E. \& Carter, L. (2018) Utilising Virtual Reality in alcohol studies. Health Education Journal, 77(2), 212-225. doi: $10.1177 / 0017896917743534$

Feldman, R. S. (2011). Treatment of Psychological Disorders. Essentials of Understanding Psychology (9. Edition) in (s. 482-515). New York: McGraw-Hill Education.

Gega, L. (2017). The virtues of virtual reality in exposure therapy. The British Journal of Psychiatry, 210, pp.245-246. doi: 10.1192/bjp.bp.116.193300.

Gonçalves, R., Pedrozo, A. L., Coutinho, E. S. F., Figueira, I. \& Ventura, P. (2012). Efficacy of virtual reality exposure therapy in the treatment of PTSD: a systematic review. PLOS ONE 7(12): e48469. https://doi.org/10.1371/journal.pone.004846.

Hadley W, Houck CD, Barker DH, et al. (2014). Eliciting affect via immersive virtual reality: A tool for adolescent risk reduction. Journal of Pediatric Psychology 39(3):pp.358368.

Jang, D. P., Kım, I. Y., Nam, S. W., Wiederhold, B. K., Wiederhold, M. D. \& Kım, S. I. (2002). Analysis of Physiological Response to Two Virtual Environments: Driving and Flying Simulation. Cyberpsychology \& Behavior, 5(1), pp.11-18.

Jerdan S. W., Grindle M., Van Woerden H. C. \& Kamel Boulos M. N. (2018). Head-Mounted Virtual Reality and Mental Health: Critical Review of Current Research. JMIR Serious Games, 6(3), DOI: $10.2196 /$ games.9226 https://games.jmir.org/2018/3/e14/

Nolen-Hoeksema, S. (2014). Substance Use and Gambling Disorders. Abnormal Psychology, (6. Edition). New York: McGraw-Hill Education.

Motraghi, T. E., Seim, R. W., Meyer, E. C. \& Morissete, S. B. (2014). Virtual reality exposure therapy for the treatment of posttraumatic stress disorder: A methodological review using Consort guiedelines. Journal of Clinical Psychology, 70(3),pp. 197208, doi: $10.1002 /$ jclp.22051. 